\title{
Investigation of Partial Discharges at the High Voltage Electric Motor Bars
}

\author{
Gediminas Dauksys $^{1,2}$, Audrius Jonaitis ${ }^{1}$, Saulius Gudzius ${ }^{1}$, Alfonsas Morkvenas ${ }^{1}$ \\ ${ }^{I}$ Department of Electric Power Systems, Kaunas University of Technology, \\ Studentu St. 48, LT-51367 Kaunas, Lithuania \\ ${ }^{2}$ Faculty of Engineering Science, Kaunas Technical College, \\ Tvirtoves al. 35, LT-50155 Kaunas, Lithuania \\ gediminas.dauksys@gmail.com
}

\begin{abstract}
It is well known the use of on-line partial discharge (PD) measurements as an indicator of stator winding insulation condition. The scheduled PD measurements could be used as a test to evaluate the quality of the equipment. The test results could help to diagnose the insulation problems in motors and generators for corresponding action before failure occurs. Although a number of PD measurement methods exists, but the tests results of on operating rotating machines can be influenced by conditions such as humidity, temperature, terminal voltage, and load. This paper describes the development of PD imitation mathematical model in stator insulation. The experimental investigation with physical model was performed for adequacy assessment. The capacitive sensor was used for PD online monitoring.
\end{abstract}

Index Terms-Condition monitoring; electric field; induction motors; insulation; partial discharges.

\section{INTRODUCTION}

Partial Discharge (PD) is an electrical discharge that does not completely bridge the space between two conducting electrodes. It occurs across a portion of the insulation between two conducting electrodes. PD activity can initiate under normal working conditions in high voltage equipment where the insulation condition has deteriorated with age, has been aged prematurely by thermal or electrical overstressing or due to improper installation. Partial Discharge is low energy electrical activity that can have very serious implications. Although each discharge is small, they are a very localized and can happen many times every second [1]. Over time this can cause damage such that the insulation becomes so weak that it fails. Partial discharge is generally accepted as an important cause of long term degradation and eventual failure of electrical insulation The point of the PD appearance usually is in the weakest place of insulation (for example - dewy insulation or contaminated with impurities). PD can also occur along the boundary between different insulating materials [2].

PD measurement as the test method has been used for more than 80 years as a factory quality control tool to detect the manufacturing defects that could eventually lead to equipment failure [3]. Insulation of high voltage rotating

Manuscript received 24 August, 2015; accepted 14 December, 2015 electric machines could change its properties due to various factors: vibrations, high temperatures, heating and cooling cycles, operating voltage, overvoltage's, pulse and dynamic loading [4], [5]. The outdoor factors (such as: moisture, chemical compounds, various types of radiations, impurities) also can make influence to the deterioration of insulation. Life time and stability of equipment's insulation depends on intensity and duration of thermal, electrical and mechanical stresses.

Deterioration of stator winding insulation is one of the main break causes of big motors and generators rated $6 \mathrm{kV}$. Over the past several years, a number of practical methods are created for measuring the PD activity in the high voltage insulation of stator windings. One of the most important factors which influences the insulation's life time is temperature. Due to high temperatures, processes of thermaloxidative in high voltage insulation destruction take quicker action. That can usually cause the decrease of mechanical strength; reduce of elasticity and damage of fleet components, what can be the reason for the formation of gas filled cavities in high voltage solid insulation [6], [1].

\section{ON-Line MONITORING OF PARTIAL Discharges}

There are a number of various methods for measurement of the PD activity in stators or motors windings. The most convenient methods are those which can be implemented during normal operation of the machine, since they are more economical and helps to avoid the cost of outages. During the last 20 years some PD measurement methods are presented which make on-line PD measurements allowing non-specialized enterprise workers easier to perform and interpret tests without reducing the reliability perform the test [7], [8]. PD measurement are widely used to diagnose the quality and condition of the electrical insulation in operating equipment such as switchgear, transformers, cables also in motor and generator stator windings [9].

The scientists of Canadian Electricity Association (CEA) have made a number of investigations with big power hydro generators. The machines stator bars are insulated with thermosetting material. This association for on-line PDs measurement offer partial discharge analyser (PDA) with differentially-connected permanent couplers [10]. The 
couplers are assembled with the stator winding. This installation allows detecting the major types of PD activity in hydro generators with minimal operator involvement. Other detection is possible while use of couplers on the isolated phase bus of high speed, hydrogen-cooled machines [11]. That research show, that differential couplers are not practical in the big rotating machines. However directional coupler systems are more sensitive for noise especially when employing the technique for cancelling noise from the power system that is used in the original PDA design. The PD measurement system is insulated from the noise. PD analyser can be used to define the great and phase angle of the PD activity.

Some authors present new technique for the remote online PD monitoring of the stator insulation high-voltage rotating machines. The technique applies wideband, ferritebased high frequency current transformer sensors and high resolution measurement technology [12]. This remote PD monitoring technique has significant advantages when monitoring motors which are located in Ex hazardous gas zones in oil and gas and petrochemical facilities.

Semi-conductive layer is often used for PD reduce in the stator winding [13]. This layer suppress the PDs happened in the slot. However, due to electromagnetic force while the motor is running, slot discharge is still one of the main causes of stator insulation degradation.

On-line continuous PDs measurements of medium voltage substations are the similar as PDs measurements of rotating machines. We can used multiple sensors for additional noise reduction and localizing $P D$ activity for measurements made in higher frequency bands [14]. An experimental investigation of the behaviour of PDs occurring in insulation cavities under influence of different voltage, temperature and electrical field conditions is presented in this paper. The main equipment used for the experimental investigation consists of the PDA and capacitive sensor. The latter is superior comparing with permanent or directional couplers in terms of simplicity and price, and because there is no need to install couplers on the stator windings.

\section{Model of PARTIAL Discharges Process IN INSULATION}

The mathematical model was created for analysis of phenomenon of PDs occurring in insulation of electrical motor stator. The model describes the winding put in magnetic circuit slot of stator (Fig. 1). The model consists of two capacitors connected in series, one of which corresponds to capacitance of insulation and the second one corresponds to capacitance of defect. The phenomenon of PD in the defect is modelled by spark gap connected in parallel to the later capacitor.

When alternating voltage $U_{\text {ins }}$ is connected to the described circuit, the capacitors collect the charge $q$. If charging voltage exceeds breakdown voltage of spark gap, the gap breaks down and the capacitor discharges. As the voltage connected to the model is alternating voltage, charging-discharging process repeats every half cycle.

Capacity of sphere shape defect is expressed by

$$
C=4 \pi \varepsilon_{0} \varepsilon_{\mathrm{ins}} d_{\mathrm{def}},
$$

where $\varepsilon_{0}$ is the permittivity of vacuum; $\varepsilon_{\text {ins }}$ is the permittivity of insulation; $d_{\text {def }}$ is the thickness of insulation defect.

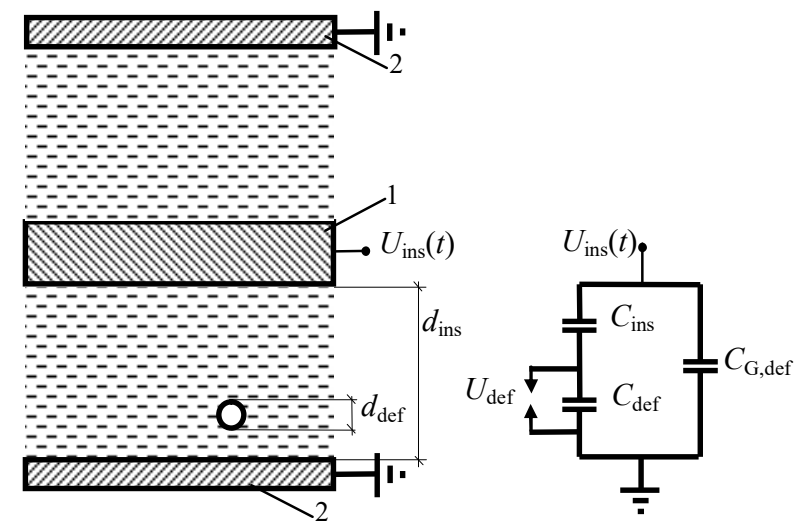

Fig. 1. Physical representation and circuit of partial discharge model: 1 conductor of the winding; 2 - magnetic circuit of stator; $d_{\text {def }}-$ defect diameter; $d_{\text {ins }}-$ insulation thickness; $U_{\text {ins }}(t)$ - insulation voltage; $U_{\text {def }}-$ defect breakdown voltage; $C_{\text {ins }}-$ insulation capacitance; $C_{\text {def }}-$ defect specific capacitance; $C_{\mathrm{G} \text {,def }}$ - insulation geometrical capacitance.

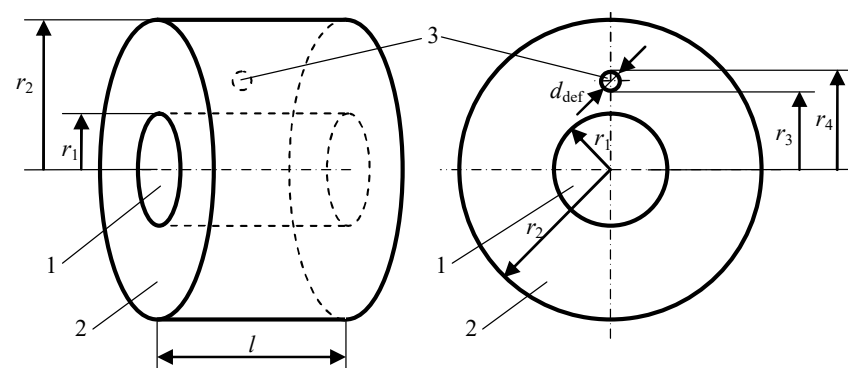

Fig. 2. Geometrical representation of round winding: 1 - conductor; $2-$ insulation; 3 - defect.

Capacity of insulation of round conductor is expressed by

$$
C=\frac{2 \pi \varepsilon_{0} \varepsilon_{i n s} \times l}{\ln \left(\frac{r_{2}}{r_{1}}\right)}
$$

where $l, r_{1}$ and $r_{2}$ are the length of winding, radius of conductor and radius of insulation, corresponding to Fig. 2.

The defect in uniform electrical field $(\mathrm{E}=$ const $)$ is affected by voltage

$$
U_{\mathrm{def}, \mathrm{E}}=\frac{\varepsilon_{\mathrm{ins}} U_{\mathrm{ins}} d_{\mathrm{def}}}{d_{2}+\varepsilon_{\mathrm{ins}} d_{\mathrm{def}}},
$$

where $d_{2}$ is the total thickness of insulation without defect

$$
d_{2}=d_{\mathrm{ins}}-d_{\mathrm{def}}
$$

The defect in non-uniform electrical field ( $\mathrm{E} \neq \mathrm{const})$ is affected by voltage

$$
U_{\mathrm{def}}=\int_{r_{3}}^{r_{4}} \varepsilon_{\mathrm{ins}} E_{\mathrm{ins}} \mathrm{d} r=\frac{\varepsilon_{\mathrm{ins}} U_{\mathrm{ins}}}{\frac{1}{r_{1}}-\frac{1}{r_{2}}} \times\left(\frac{1}{r_{3}}-\frac{1}{r_{4}}\right),
$$

where $E_{\text {ins }}$ is electrical voltage of the insulation; $r$ is the radius of the winding; $r_{1}, r_{2}, r_{3}, r_{4}$ are the dimensions corresponding to Fig. 2. 
The charge of PD collected at the defect equals to

$$
q=U_{\mathrm{def}} C_{\mathrm{ins}}
$$

The voltage of PD in the slot of stator insulation is calculated according to (3) and (4). The voltage dependence from $U_{\text {ins }}$ is shown in Fig. 3.

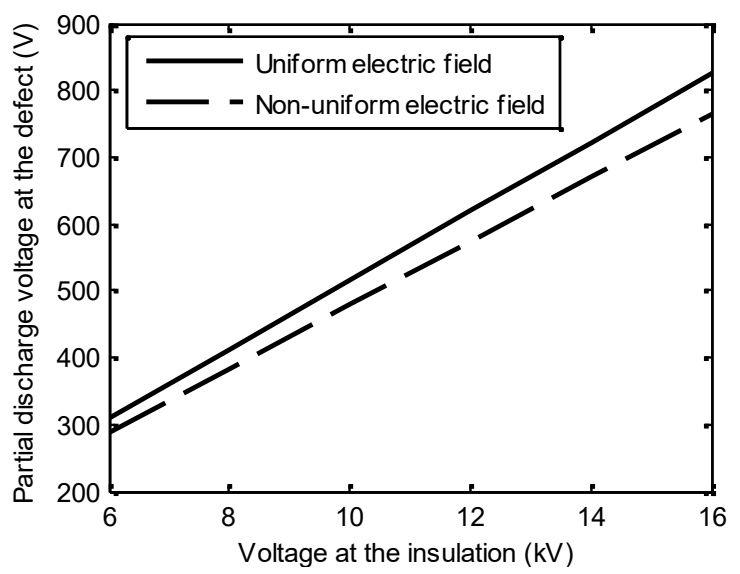

Fig. 3. Insulation defect breakdown voltage as a function of voltage at the insulation.

The PDs charge was calculated by using (5). The charge depends proportionally to the voltage at the insulation. Calculations show that charge in the uniform electrical field is bigger than in non-uniform electrical field (Fig. 4).

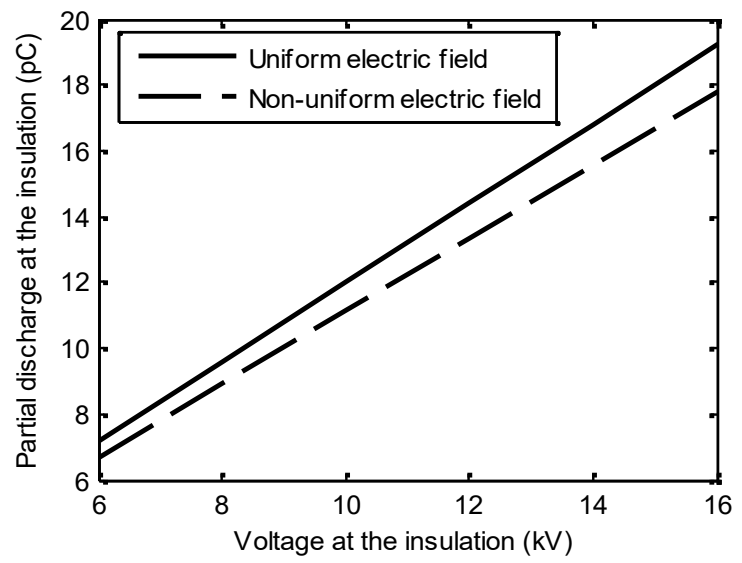

Fig. 4. Charge of PD as a function of voltage at the insulation.

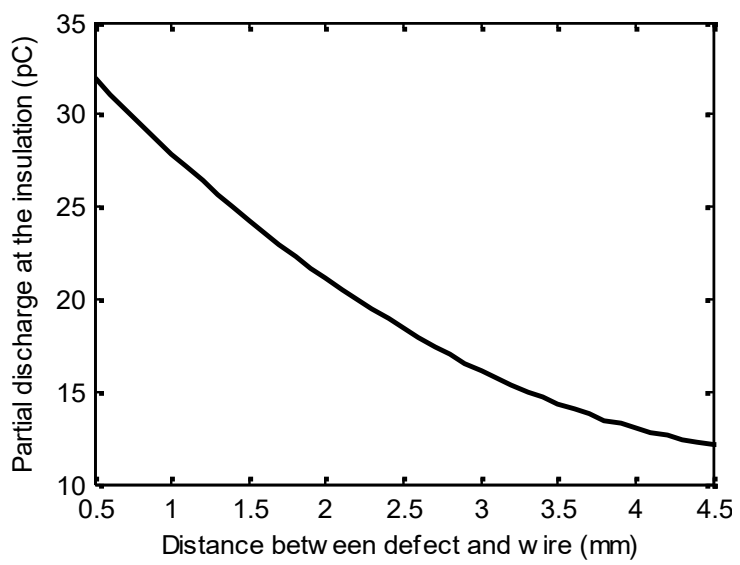

Fig. 5. Dependence of PDs charge on distance of defect to conductor.

Calculations shown in Fig. 3 and Fig. 4 when place of defect at the insulation is stable. When the place of defect is not stable, the change of PDs charge is exponential (Fig. 5).

\section{EXPERIMENTAL INVESTIGATION}

Experimental test of PD characteristics was performed for the $6 \mathrm{kV} 500 \mathrm{~kW}$ induction motor bar. The bar was put into physical model of stator magnetic circuit made of $0.5 \mathrm{~mm}$ electrical steel. The stator magnetic circuit model was grounded and the voltage of particular level was supplied to the bar. Measurements were performed by nonelectrical induction method. The temperature of bar was changed from $20{ }^{\circ} \mathrm{C}$ to $60^{\circ} \mathrm{C}$ with $10^{\circ} \mathrm{C}$ intervals. The PDs were detected by inductive device LDP-5 (differential LEMKE probe). The functional diagram of experiment equipment is presented in Fig. 6.

The testing object does not contain high density metal screen. That allows to measure PD with capacitive sensor directly and not through the grounding strip. The distance of the probe to the bar was $10 \mathrm{~cm}$. During the test, voltage was increased with $1 \mathrm{kV}$ steps.

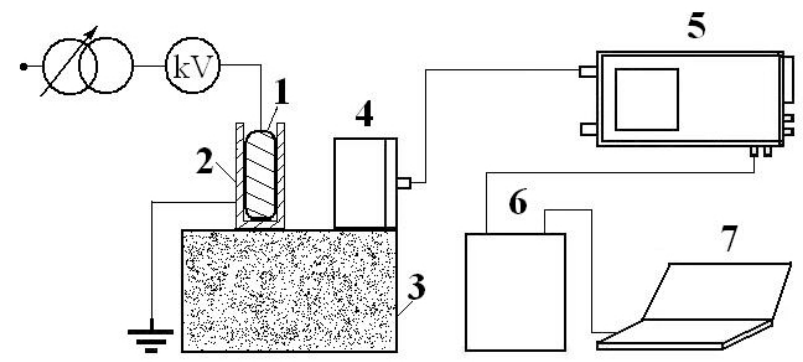

Fig. 6. Functional diagram: $1 \mathrm{kV}-6 \mathrm{kV}, 500 \mathrm{~kW}$ multiturn coil; 2 - model simulating the core slot of stator; 3 - insulation material; 4 - capacitive sensor; 5 - device LDP-5 (differential LEMKE probe); 6 - electronic oscillograph; 7 - laptop.

In order to reduce the measurement error, every measure was performed three times and average value was calculated. The measured and approximated data are shown in Fig. 7 and Fig. 8.

The temperature of insulation was rising with a current transformer. The generated current was 60 A-100 A. Diapason of temperature $30{ }^{\circ} \mathrm{C}-60{ }^{\circ} \mathrm{C}$ (Fig. 7).

The PDs change in the bar when insulation temperature $15^{\circ} \mathrm{C}$ is shown at Fig. 8. The optimal results with the relatively lowest number of PDs detected at the $10 \mathrm{kV}$ voltage.

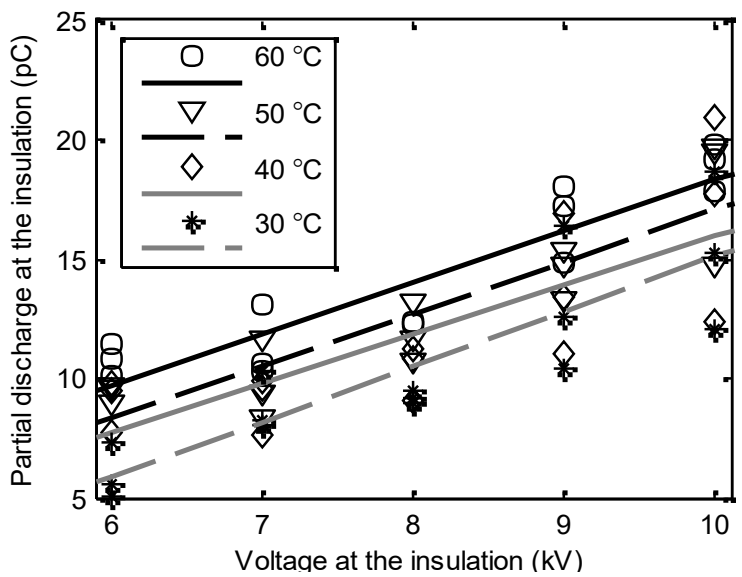

Fig. 7. PDs charge as a function of voltage at different insulation temperatures.

The experimental data were used to evaluate adequacy of mathematical model. Validation was performed by analysing 
PDs charge as a function of insulation voltage, i.e. $q=$ $f\left(U_{\text {ins }}\right)$. These functions are shown in Fig. 4 and Fig. 8. The measured PDs occurred at uniform and non-uniform electrical fields. To estimate theoretical value of PDs charge, the mean value at uniform and non-uniform electrical fields and the same voltage was calculated. The relative errors were estimated for every measured voltage value. If the dimensions of the insulation defect are the same at uniform and non-uniform electrical fields, the obtained relative error is less than $10 \%$ only for half of measurements. Calculation results are presented in Table I.

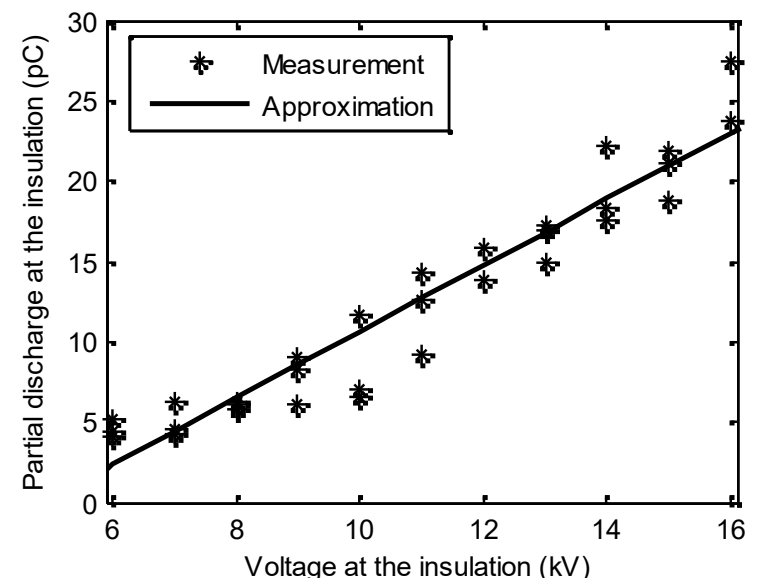

Fig. 8. Measured and approximated data of partial discharge at the insulation as a function of applied voltage.

TABLE I. RESULT OF SIMULATION WHEN DDEF. CONSTANT.

\begin{tabular}{|c|c|c|c|c|c|c|}
\hline Parameter & \multicolumn{6}{|c|}{ Value } \\
\hline$U_{\text {ins }}, \mathrm{kV}$ & 6 & 8 & 10 & 12 & 14 & 16 \\
\hline$d_{\text {def } E=\text { const }}, \mathrm{mm}$ & 0.068 & 0.068 & 0.068 & 0.068 & 0.068 & 0.068 \\
\hline$d_{\text {def } E \neq \text { const, } \mathrm{mm}}$ & & & & & & \\
\hline$q_{\text {experimental }}, \mathrm{pC}$ & 4.54 & 6.02 & 8.39 & 14.50 & 19.35 & 24.95 \\
\hline$q_{\text {modelled }} \mathrm{pC}$ & 4.73 & 6.31 & 7.89 & 9.46 & 11.04 & 12.62 \\
\hline Relative error $\delta, \%$ & 4.19 & 4.82 & 5.96 & 34.76 & 42.95 & 49.42 \\
\hline
\end{tabular}

If size of defect $d_{\text {def }}$ in non-uniform electrical field increases, model error at $12 \mathrm{kV}-16 \mathrm{kV}$ is less than $5 \%$ in $50 \%$ of measurements and less than $10 \%$ of other $50 \%$ of measurements. Calculation results are presented in Table II.

TABLE II. RESULT OF SIMULATION WHEN DDEF. IS VARIABLE.

\begin{tabular}{|c|c|c|c|c|c|c|}
\hline Parameter & \multicolumn{6}{|c|}{ Value } \\
\hline$U_{\text {ins }}, \mathrm{kV}$ & 6 & 8 & 10 & 12 & 14 & 16 \\
\hline$d_{\text {def } E=\text { const }}, \mathrm{mm}$ & 0.068 & 0.068 & 0.068 & 0.068 & 0.068 & 0.068 \\
\hline$d_{\text {def } E \neq \text { const }}, \mathrm{mm}$ & 0.068 & 0.068 & 0.068 & 0.090 & 0.110 & 0.138 \\
\hline 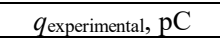 & 4.54 & 6.02 & 8.39 & 14.50 & 19.35 & 24.95 \\
\hline$q_{\text {modelled, }} \mathrm{pC}$ & 4.73 & 6.31 & 7.89 & 14.51 & 19.47 & 26.16 \\
\hline Relative error $\delta, \%$ & 4.19 & 4.82 & 5.96 & 0.60 & 0.62 & 4.63 \\
\hline
\end{tabular}

\section{CONCLUSIONS}

This work focused on investigating the PD in solid insulation of high voltage electric motors. The insulation quality we can identify from insulation temperature and insulation voltage. This work has proven that the estimated adequacy of mathematical model depends on the range of insulation voltage. When diameter of the defect is constant and equals $0.068 \mathrm{~mm}$, the model's accuracy exceeds $93 \%$ for insulation voltage of $6 \mathrm{kV}-10 \mathrm{kV}$. If the voltage is higher, the model's accuracy drastically decreases. If the size of defect in non-uniform electrical field increases, model accuracy is higher than $93.6 \%$. The PD's charge increases by $20.03 \%$ when insulation temperature increases $10{ }^{\circ} \mathrm{C}$. Analysis shows that PDs voltage increases from $300 \mathrm{~V}$ to $820 \mathrm{~V}$ when insulation voltage changes from $6 \mathrm{kV}$ to $16 \mathrm{kV}$. There is a high potential for it to be applied in practically of high voltage motors insulation. In practice we can establish the resource of solid insulation and repair the motor in real time.

\section{REFERENCES}

[1] M. Farahani, H. Borsi, E. Gockenbach, M. Kaufhold, "Partial discharge and dissipation factor behavior of model insulating systems for high voltage rotating machines under different stresses", IEEE Electrical Insulation Magazine, vol. 21, no. 5, pp. 5-19, 2005. [Online]. Available: http://dx.doi.org/10.1109/MEI.2005.1513425

[2] J. Kurimsky, I. Kulcunova, R. Cimbala, "Partial discharge analysis for insulation systems of electric rotating machines with various voltage stress", Acta Electrotechnica et Informatica, vol. 8, no. 4, pp. 64-67, 2008.

[3] G. C. Stone, "A perspective on online partial discharge monitoring for assessment of the condition of rotating machine stator winding insulation”, IEEE Electrical Insulation Magazine, vol. 28, no. 5, pp. 8-13, 2012. [Online]. Available: http://dx.doi.org/10.1109/MEI. 2012.6268437

[4] P. Valatka, G. Dauksys, "Investigation of the voltage influence on partial discharge characteristic parameters in solid insulation", in Proc. of the XX Int. Conf. Electromagnetic Disturbances (EMD 2010), Kaunas, 2010, pp. 155-158.

[5] M. S. Hapeez, A. F. Abidin, H. Hashim, N. R. Hamzah, M. K. Hamzah, "Analysis and classification of different types of partial discharges by harmonic orders", Elektronika ir Elektrotechnika, vol. 19, no. 9, pp. 35-41, 2013. [Online]. Available: http://dx.doi.org/10.5755/j01.eee.19.9.2545

[6] I. M. Bortnik, High Voltage Engineering. Moscow: Energoatomizdat, 1993, p. 543.

[7] S. R. Campbell, G. C. Stone, H. G. Sedding, G. S. Klempner, W. McDermid, R. G. Bussey, "Practical on-line partial discharge tests for turbine generators and motors", IEEE Trans. Energy Conversion, vol. 9, no. 2, pp. 281-287, 1994. [Online]. Available: http://dx.doi.org/10.1109/60.300147

[8] B. A. Loyd, S. R. Campbell, G. C. Stone, "Continuous on-line partial discharge monitoring of generator stator windings", IEEE Trans. Energy Conversion, vol. 14, no. 4, pp. 1131-1138, 1999. [Online]. Available: http://dx.doi.org/10.1109/60.815038

[9] G. S. Stone, H. G. Sedding, M. J. Costello, "Application of partial discharge testing to motor and generator stator winding maintenance", IEEE Trans. Industry Applications, vol. 32, no. 2 , pp. 459-464, 1996. [Online]. Available: http://dx.doi.org/10.1109/ 28.491498

[10] W. McDermid, "Insulation systems and monitoring for stator windings of large rotating machines", IEEE Electrical Insulation Magazine, vol. 9, no. 4, pp. 7-15, 1993. [Online]. Available: http://dx.doi.org/10.1109/57.223893

[11] J. C. Bromley, W. McDermid, "Monitoring rotating machine insulation with the CEA PDA through the use of directional couplers", in Proc. of the 18th Electrical/Electronics Insulation Conf., Chicago, 1987, pp. 120-124.

[12] L. A. Renforth, D. Clark, S. Goodfellow, R. Armstrong, P. S. Hamer, "A new technique for the remote partial discharge monitoring of the stator insulation of high-voltage motors located in 'Ex' (hazardous gas) locations", in IEEE-PCI Conf. 2012, New Orleans, 2012, pp. 1 10.

[13] S. Jiancheng, L. Chuanyang, L. Lingyan, L. Zhipeng, Y. B. Xiao, Y. Haoyuan, "Slot discharge pattern of $10 \mathrm{kV}$ induction motor stator coils under condition of insulation degradation", IEEE Trans. Dielectrics and Electrical Insulation, vol. 20, no. 6, pp. 2091-2098, 2013. [Online]. Available: http://dx.doi.org/10.1109/TDEI.2013. 6678857

[14] I. Blokhintsev, C. L. Patterson, B. J. Cassidy, A. H. Loesch, "Advantage of On-Line Partial Discharge continuous monitoring of medium voltage substation", in IEEE Electrical Insulation Conf. Montreal, 2009, pp. 153-158. [Online]. Available: http://dx.doi.org/ 10.1109/eic.2009.5166335 